\title{
Geometrical optimization for a photovoltaic installation equipped with flat reflectors based on plane of array estimations
}

\author{
Christine Abdel Nour ${ }^{1,2,4,}$, Anne Migan-Dubois ${ }^{1}$, Jordi Badosa ${ }^{2}$, Vincent Bourdin ${ }^{3}$, Claude Marchand ${ }^{1}$, \\ and Tilda Akiki ${ }^{4}$ \\ ${ }^{1}$ GeePs, CNRS UMR 8507, CentraleSupélec, Univ Paris-Sud, Sorbonne Université, 11 rue Joliot-Curie, Plateau de Moulon, \\ 91192 Gif-sur-Yvette Cedex, France \\ ${ }^{2}$ LMD, Institut Pierre-Simon Laplace, CNRS, École Polytechnique, 91128 Palaiseau Cedex, France \\ ${ }^{3}$ LIMSI, UPR 3251 CNRS, Bâtiment 508, Rue John von Neumann, 91405 Orsay Cedex, France \\ ${ }^{4}$ Université Saint Esprit de Kaslik, USEK, Département de génie électrique et électronique, BP446 Jounieh, Lebanon
}

Received: 20 April 2019 / Received in final form: 19 November 2019 / Accepted: 10 December 2019

\begin{abstract}
In order to design, manage and optimize the performance of a photovoltaic (PV) installation and establish a precise power production estimation, irradiance on the plane of array (POA) in relation with the geometrical characteristics of the PV modules installation occupies a high importance. This study focuses on the development of an estimation model of the POA irradiance for a photovoltaic installation equipped with flat reflectors. The model includes solar irradiance components (global, direct and diffuse), geometrical parameters and geographical characteristics of the PV installation. Experimental validations have been performed with measurements taken at the SIRTA Observatory $\left(48.7^{\circ} \mathrm{N}, 2.2^{\circ} \mathrm{E}\right)$ in Palaiseau, France, for the period starting from June 2017 to June 2018. Results show mean absolute errors (relative to the mean) of $6 \%$ and $7 \%$ for an installation without and with planar reflector. Finally, we present several geometrical optimization strategies of the PV-reflector installation relying on two major variables: the reflector's length $(L R)$ compared to the length of the PV module $\left(L_{\mathrm{PV}}\right)$ and the tilt angle adjustment frequency (monthly, seasonally, fixed) of the system (for both PV and the reflectors). The objective of such optimization is to discuss about a reasonable configuration to achieve a maximum POA irradiance. Results show that the length of the mirrors highly affects the efficiency and performances of the PV-Reflector system and the annual gain increased from $8.5 \%$ to $28.7 \%$ when going from $L_{R}=L_{P V} / 2$ to $L_{R}=2 \times L_{P V}$ compared to a monthly-optimized installation without mirrors. As for the adjustment frequency, we show that a monthly-varied architecture is the most advantageous option with a 28.2 and $31.6 \%$ increasing in annual gain compared to a seasonal varied or fixed ones, respectively.
\end{abstract}

Keywords: plane of array irradiance / PV-reflector system / flat reflectors / irradiance estimation / geometrical optimization

\section{Introduction}

The greenhouse gas emissions occupy a major concern our societies are facing nowadays.

One of the crucial factors contributing to this problem are fossil fuels emissions. Thus, the substitution of these resources by renewable energies is a major challenge occupying the interest of governments at a worldwide level.

According to SolarPower Europe 2019, a 36\% increasing in solar power plants installation has occurred between 2017 and 2018 at the European Union level ${ }^{1}$. Furthermore,

\footnotetext{
* e-mail: Christine.abdelnour@geeps. centralesupelec.fr

${ }^{1}$ C S SolarPower Europe 2019.
}

the estimated growth in solar market by 2022 is around 40 GW. The price of solar power production is dropping rapidly nowadays allowing an important energy system shifting from conventional fossil fuels to clean energy in the upcoming years.

For identical PV installations in different geographical locations, power generation won't be the same. This is due to the difference in the solar irradiance flux reaching the PV modules, the atmospheric conditions, the environment of the installation and geometrical aspects. Thus, an adequate plane of array irradiance study must be performed considering all the mentioned parameters in order to have an accurate system's efficiency assessment.

In order to improve the operating performances of solar installations, high efficiency photovoltaic systems are under development. In fact, adding reflectors in front of 

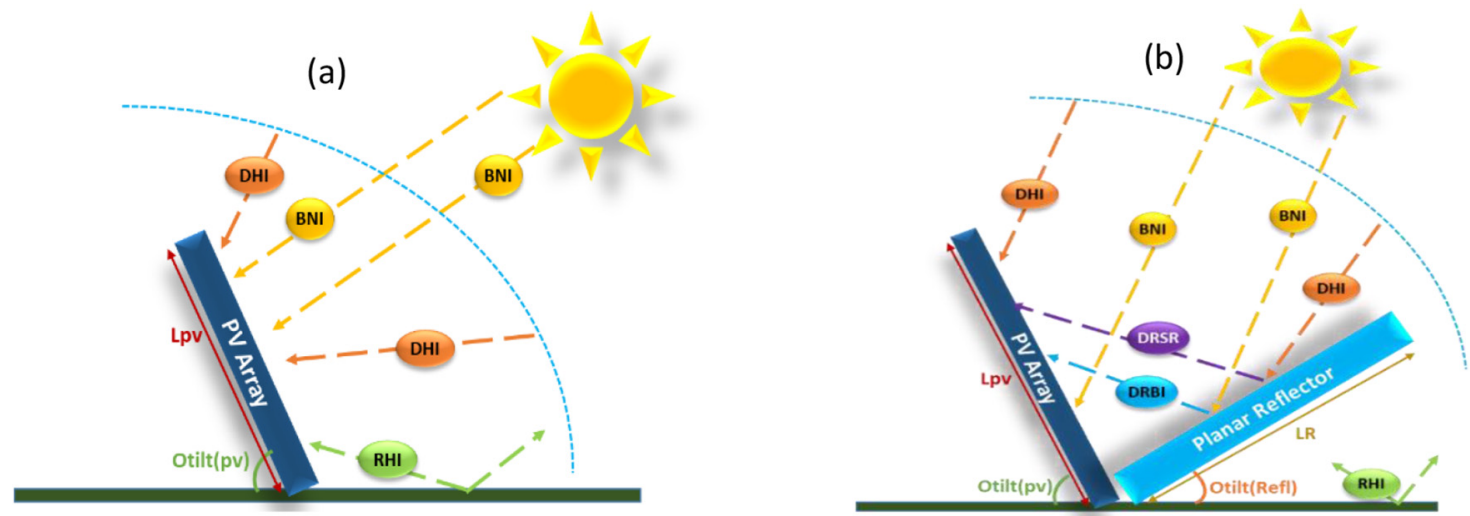

Fig. 1. Irradiances characterizing a classical PV system architecture (a) and a PV-reflector system architecture (b).

the PV arrays contributes in increasing the incident irradiance on the modules and thus increasing the electrical production efficiency. For instance, some research studies about flat reflectors technologies with fixed and automated mirrors topologies are conducted [1-3]. One of the objectives of such studies aims to define adequate settings for PV-reflector systems with fixed inter-rows space as well as the impact of string mismatch of such systems [2]. According to [2], adding planar reflectors represents a low cost solution where during clear sky days, the produced energy can increase up to $35 \%$. The evaluation of flat booster reflectors in various $\mathrm{PV}$ installations and different alternative arrangements was performed as well in [3]. For example, we can cite ALEPH project (Amelioration of photovoltaic efficiency) conducted in SIRTA [4] aiming to increase the system's yield by adding inter-row planar reflectors. Furthermore, an industrial PV system equipped with planar reflectors was developed by TENKSOLAR, Bloomington, United States [5] focusing on the importance of flat large area reflectors concept. Other studies are performed also describing the advantages of the flat reflectors by increasing the incident solar flux on the solar thermal systems. In Sweden, the annual irradiance can be increased between $8 \%$ and $17 \%$ by adding flat reflectors according to a study conducted considering the evenly distributed radiation [6]. Moreover, according to a research performed in different locations in USA the irradiance can be increased up to $9 \%$ for an optimized fixed PV-reflector configuration [7].

One advantage of a planar reflector PV system is that it represents a low concentration technology compared to the parabolic concentrators. Therefore, with flat reflectors the temperature negative effect is not much significant, thus, a cooling procedure is not required which contributes in reducing the system's cost [8]. Furthermore, for PVreflector system, we do not need a precise sun tracking equipment, which is not the case of CPV technology requiring high accuracy and reliability for tracking systems, automatically leading to an increased cost.

The main objective of this work is elaborating a POA irradiance estimation model for a PV system equipped with flat reflectors. The system's efficiency is investigated within the frame of geometrical optimization case studies relying on two parameters: the length ratio between the reflector and the PV module and the architecture variation frequency. In order to meet the highest performances according to the solar profile the optimization results were retrieved. For that purpose, the case studies relied on the climatic data issued from SIRTA [9], [10] at Palaiseau, France.

\section{Methodology}

\subsection{Modelling methodology}

The solar radiation received by a tilted surface with respect to the horizontal surface is composed of three elements:

- The direct solar radiation following a straight trajectory from the sun to the surface of earth.

- The diffuse solar radiation scattered in the atmosphere and reaching the surface of the earth.

- The reflected radiation coming from the ground and the surrounding area (Fig. 1a).

- In case of a system equipped with flat reflector, the direct and diffuse irradiances reaching the mirror's surface to be then reflected on the PV module will be added (Fig. 1b).

A Matlab POA irradiance estimation model was developed using the measured irradiances data from SIRTA (Site Instrumental de Recherche par Télédétection Atmosphérique) observatory [9]: GHI, DHI and BNI (Fig. 2) and the irradiance reflected by the mirrors was computed as well. In addition, other parameters were considered such as the solar angles $\left(\theta_{z a}, \theta_{a}\right.$, and $\left.A O I\right)$, the geometrical position, orientation and dimensioning of the PV-Reflector architecture as well as ground and mirror's reflection properties.

\subsection{Modelling equations}

The analytical model developed through this work was based on a detailed study of solar radiation estimation [12] (Solar Engineering of thermal processes textbook). A study describing feasibility cases of using flat booster reflectors in PV installations was considered as well [3].

Angle of incidence:

$$
\begin{aligned}
A O I= & a \cos \left[\cos \left(\theta_{Z}\right) \times \cos \left(\theta_{\text {tilt }}\right)+\sin \left(\theta_{Z}\right)\right. \\
& \left.\times \sin \left(\theta_{\text {tilt }}\right) \times \cos \left(\theta_{a}-\theta_{a, \text { array }}\right)\right] .
\end{aligned}
$$




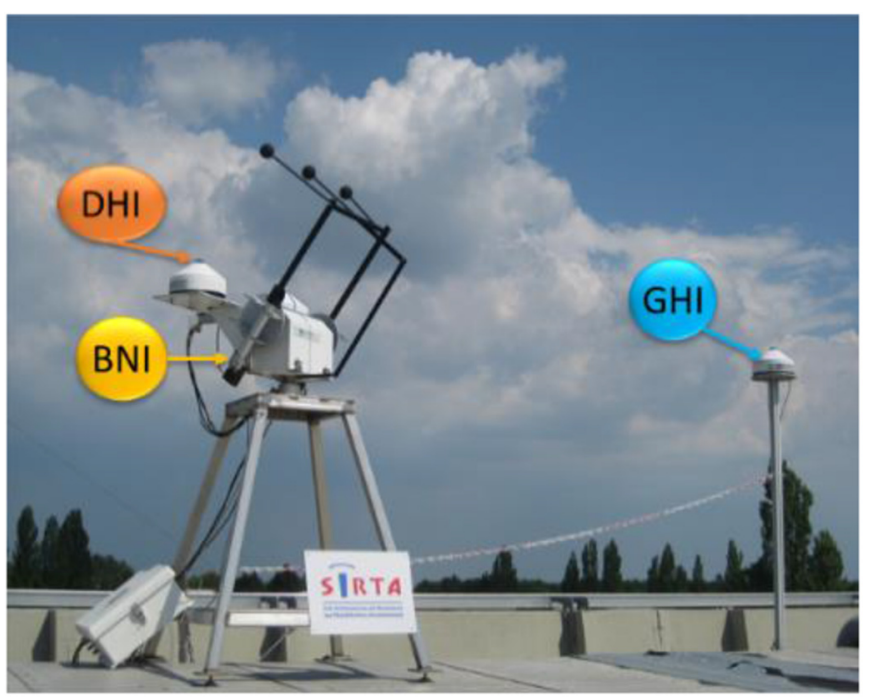

Fig. 2. Direct, diffuse and global irradiances measurement sensors, SIRTA observatory, which are part of the PAL station of the Baseline Surface Radiation Network (BSRN, https://bsrn. awi.de/).

View factor from the reflector to the PV module: $V F_{R_{P V}}$

$$
=\frac{\left(L_{P V}+L_{R}-\sqrt{\left(L_{P V}^{2}+L_{R}^{2}-2 \times L_{P V} \times L_{R} \times \cos \theta_{P V R}\right)}\right)}{2 \times L_{R}} .
$$

View factor from the PV module to the reflector:

$$
V F_{P V_{R}}=V F_{R_{P V}} \times \frac{L_{R}}{L_{P V}} .
$$

\subsubsection{Computing the plane of array irradiance considering a classical PV installation without mirrors}

The plane of array irradiance calculation is based on two main simplifications: the sky diffuse irradiance is considered isotropic (uniform in all orientations) and the ground surface is considered Lambertian (its reflectance is the same regardless of the view angle).

$$
\begin{aligned}
P O A= & \left(\frac{G H I-D H I}{\sin \left(\theta_{e l}\right)}\right) \times \cos (A O I)+D H I \\
& \times \frac{1+\cos \left(\theta_{\text {tilt }}\right)}{2}+G H I \times \rho_{g} \times \frac{1-\cos \left(\theta_{\text {tilt }}\right)}{2} .
\end{aligned}
$$

\subsubsection{Computing the plane of array irradiance considering} a PV installation equipped with flat reflectors

Ground reflected incident solar radiation:

$$
G R I S R=G H I \times \rho_{g} \times\left(\frac{1-\cos \left(\theta_{t i l t}\right)}{2}-V F_{P V_{R}}\right) .
$$

Direct reflected beam irradiance: direct irradiance reaching the mirrors to be reflected on the PV modules:

$$
D R B I=R \times B H I \times \frac{\cos \left(A O I_{R, P V}\right)}{\cos \left(\theta_{Z}\right)} .
$$

Diffuse reflected solar radiation: diffuse irradiance received by the mirrors to be reflected on the PV modules:

$$
\begin{aligned}
D R S R= & \left(1-V F_{R_{P V}}\right) \times D H I \times \frac{1+\cos \left(\theta_{R}\right)}{2} \\
& +G H I \times \rho_{g} \times \frac{1-\cos \left(\theta_{R}\right)}{2} \times R \times V F_{P V_{R}} .
\end{aligned}
$$

General equation of POA irradiance with reflectors according to the illumination height on the PV module as well as the AOI:

$$
\begin{aligned}
P O A_{\text {Mir }}= & \frac{G H I-D H I}{\sin \left(\theta_{e l}\right)} \times \cos (A O I)+D H I \\
& \times \frac{1+\cos \left(\theta_{\text {tilt }}\right)}{2}+G R I S R+D R B I+D R S R .
\end{aligned}
$$

In order to establish an accurate estimation of the plane of array irradiance with the presence of reflectors, several particular cases need to be addressed. These cases are considered according to different impacts that the reflectors could have on a PV panel and thus to the effective POA irradiance received by it:

- Case 1: The reflected irradiance from the mirror covers the highest level of the PV module length (as shown in Fig. 3a) or exceeds it. In this case, the equation (8) keeps all the terms.

- Case 2: The reflected irradiance from the mirror covers an inferior level of the PV module length (Fig. 3b), and thus we consider that $\mathrm{DRBI}=0$. In this case the irradiance mismatch effect is taken into consideration and thus the activation of bypass diodes wasn't neglected. Therefore, the direct irradiance of the reflected beams is not considered here.

- Case 3: Period where the reflector is totally or partially shading the PV module: Only the diffuse irradiance can be considered in this case (Fig. 3c). No direct irradiance component is considered. Therefore, in this case the direct irradiance (BNI) reaching the planar reflectors or the PV modules is not taken into consideration.

- Annual gain in POA irradiance added by the reflectors is calculated as follows:

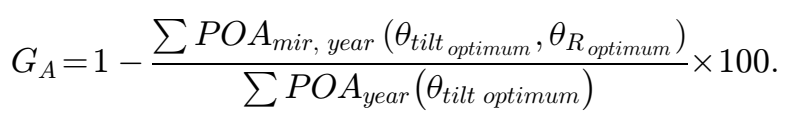

- Monthly gain in POA irradiance added by the reflectors:

$$
G_{M}=1-\frac{\sum P O A_{\text {mir,month }}\left(\theta_{\text {tilt }_{\text {optimum }}}, \theta_{R}\right)}{\sum P O A_{\text {month }}\left(\theta_{\text {tilt }}\right)} \times 100 .
$$



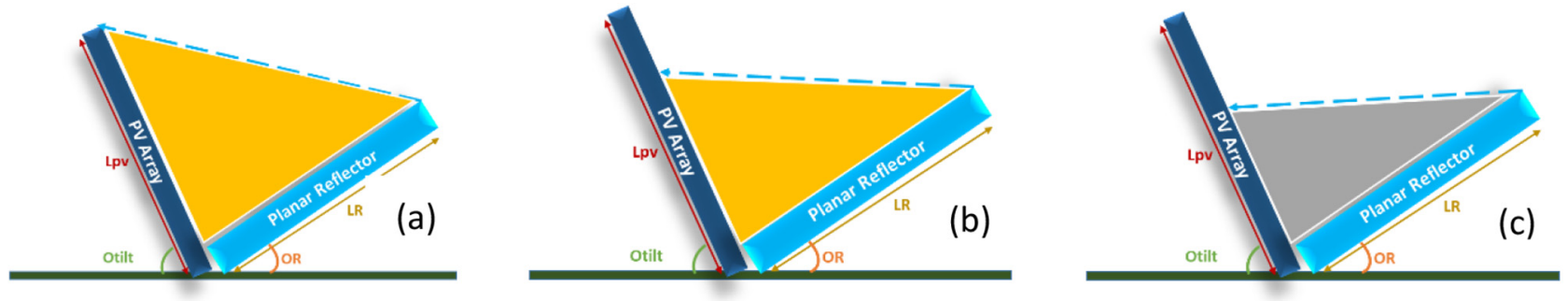

Fig. 3. Estimation of the plane of array irradiance according to the reflector: reflected irradiance reaching the highest level (a), reflected irradiance is below the highest level of the PV module (b) and causing total or partial shading on the PV module (c).

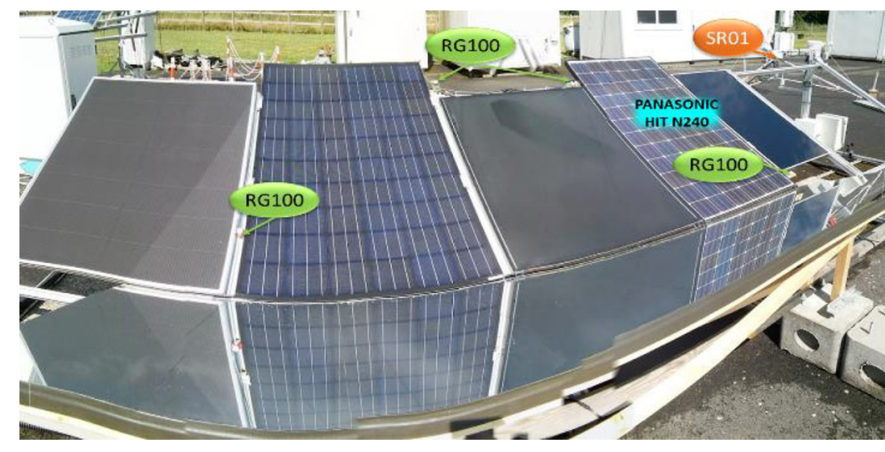

Fig. 4. Characterization test bench equipped with sensors and flat reflectors, SIRTA observatory.

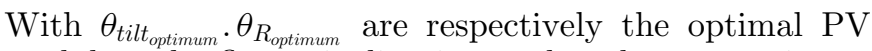
module and reflector inclination angles where a maximum POA irradiance is achieved each month.

\section{Experimental validation}

The model was validated experimentally with and without reflectors using the plane of array irradiance measurements from the SIRTA test bench $[4,9,10]$, during a campaign where measurements were recorded over 13 months (June 2017-June 2018). Flat reflectors were installed between July and October 2017 (Fig. 4) and thus two periods are considered. For PV-reflector installations, it's always desirable to have overhanging on the right and left of the PV modules on the edges in order to limit mismatch effects. In the experimental PV installation performed, the Panasonic HIT module was considered for the study. Thus, there were a large overhanging from the west of the module without a considerable one on the East side as illustrated in Figure 4. On the other hand, in the plane of array estimation model developed, infinite mirrors rows were considered. Thus, the estimation model does not consider the edge effect. We performed irradiance measurements in the plane of array using a solar pyranometer (Hukseflux SR01) and reference PV cells (SOLEMS RG100) installed at the top of the plane of array (Fig. 4). For this work, hourly averages from one-minute data are used.

\subsection{Evaluation indicators}

In the experimental validation process, we calculated error indicators in order to compare our simulation results with measurements. The indicators used are MBE, RMBE, MAE and RMAE.

$$
\begin{aligned}
& \operatorname{MBE}\left(\mathrm{W} / \mathrm{m}^{2}\right)=\frac{\sum_{i=1}^{N}\left[P O A_{\text {,measure }}(i)-P O A_{\text {,model }}(i)\right]}{N} . \\
& \operatorname{MAE}\left(\mathrm{W} / \mathrm{m}^{2}\right)=\frac{\sum_{i=1}^{N}\left|P O A_{, \text {measure }}(i)-P O A_{, \text {model }}(i)\right|}{N} .
\end{aligned}
$$

$$
R M B E=\frac{\sum_{i=1}^{N}\left[P O A_{, \text {measure }}(i)-P O A_{, \text {model }}(i)\right]}{\sum_{i=1}^{N}\left[P O A_{, \text {measure }}(i)\right]} \times 100
$$

$$
R M A E=\frac{\sum_{i=1}^{N}\left|P O A_{, \text {measure }}(i)-P O A_{, \text {model }}(i)\right|}{\sum_{i=1}^{N}\left|P O A_{\text {,measure }}(i)\right|} \times 100
$$

\subsection{Experimental validation for the installation without reflectors}

In this part, a comparison between the modelled and measured POA irradiance was performed in the absence of flat reflectors. As shown in Figure 5, the POA modelled irradiance was compared to the POA measured irradiance for the period between October 13th 2017 and June 8th 2018. The error indicators show a RMAE and RMBE values of $6 \%$ and $0.6 \%$, respectively. Notice that the sensors for GHI, DHI and BHI are located $700 \mathrm{~m}$ away from the POA irradiance measurements, therefore a certain part of the error estimation could be caused by the distance between the sensors. However, this is estimated small $\left(<3 \%\right.$ and $<15 \mathrm{~W} / \mathrm{m}^{2}$, study not shown here) as hourly averages are used in this work. 


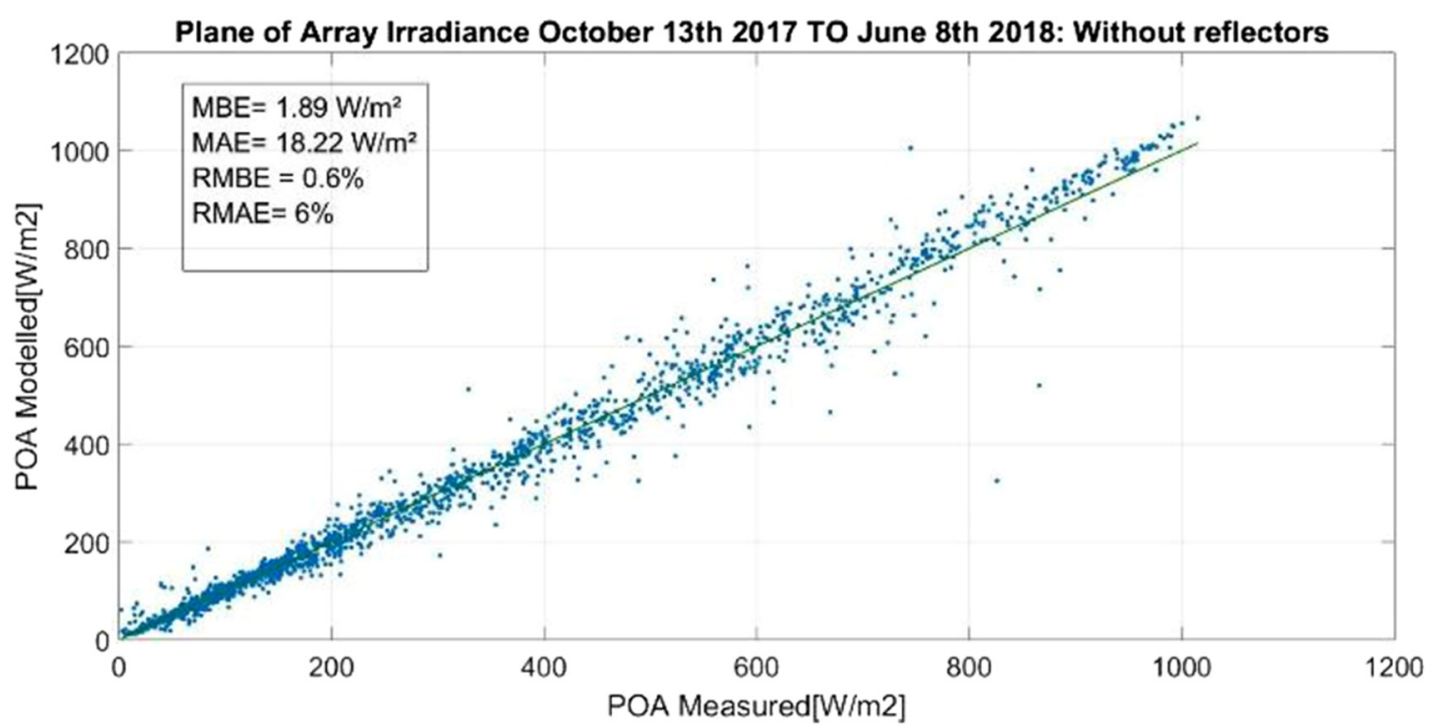

Fig. 5. Comparison between the measured and modelled POA irradiance over the period from October 13 th 2017 to June 8 th 2018 : Installation without flat reflectors.

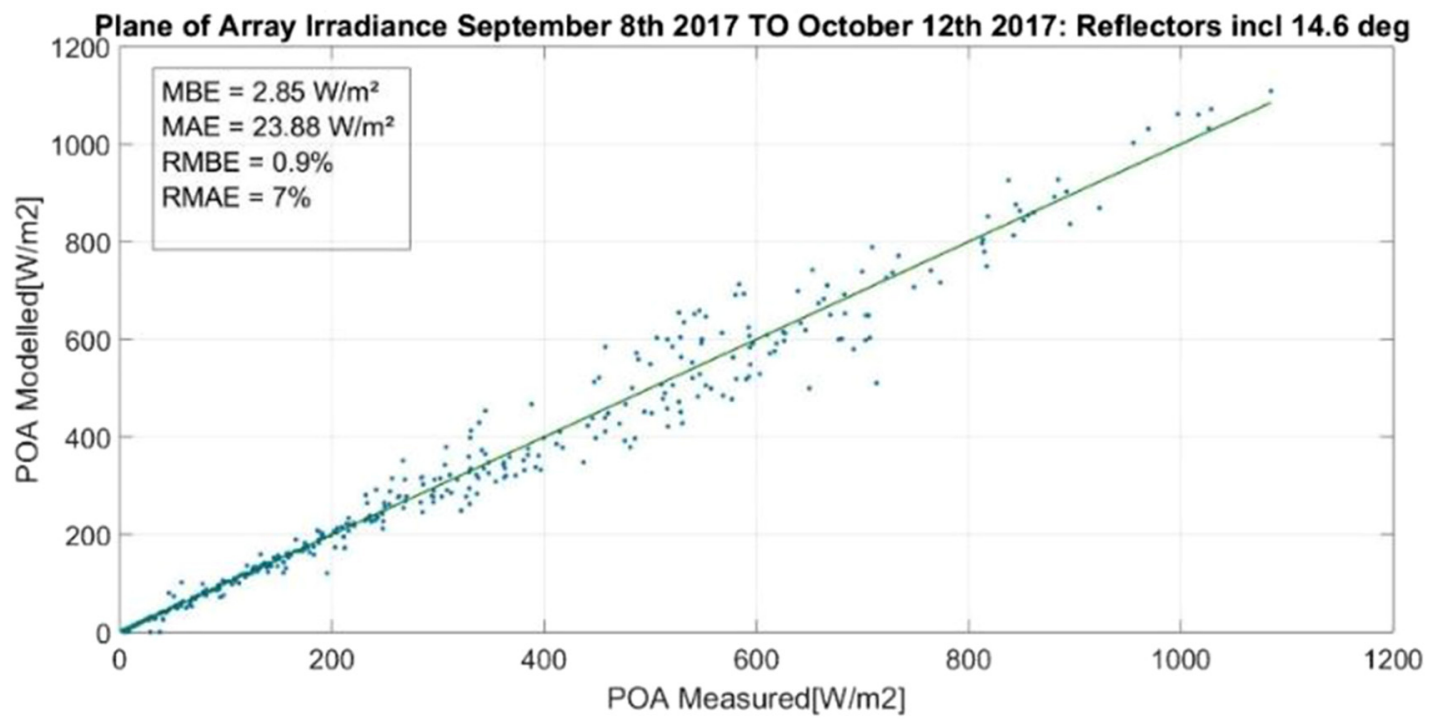

Fig. 6. POA measured vs. POA modelled irradiances (September 2017 to October 2017).

\subsection{Experimental validation for the installation with reflectors}

In this part, a comparison between the modelled and measured POA irradiance was performed in the presence of mirrors during the campaign conducted between July and October 2017 (Fig. 4). The experimental PV installation setup was composed of five PV modules from different technologies with a $26.7^{\circ}$ tilt angle to the horizontal plane. The Panasonic HIT N240 module was considered in our studies. Thus, the POA irradiance measurements were retrieved out of SR01 and RG100 sensors installed at the upper level of the Panasonic PV array. The mirrors were placed between July 25th and October 12th 2017 with a $14.6^{\circ}$ inclination to the horizontal plane.
Results are shown in Figure 6, and the obtained error indicators were $7 \%$ and $0.9 \%$ for RMAE and RMBE respectively, showing consistency with the errors obtained without reflectors, as exposed above. In all cases the bias is small, less than $1 \%$, which is relevant for the validity of the optimization work that is presented in the following sections.

\subsection{Comparison between the plane of array irradiance with and without reflectors}

Considering the experimental setup parameters performed in SIRTA, in this section we compared the POA irradiance modelled with reflectors to the modelled POA irradiance without reflectors. Thus, according to our platform, in this phase we used fixed parameters for the tilt angles of the PV 


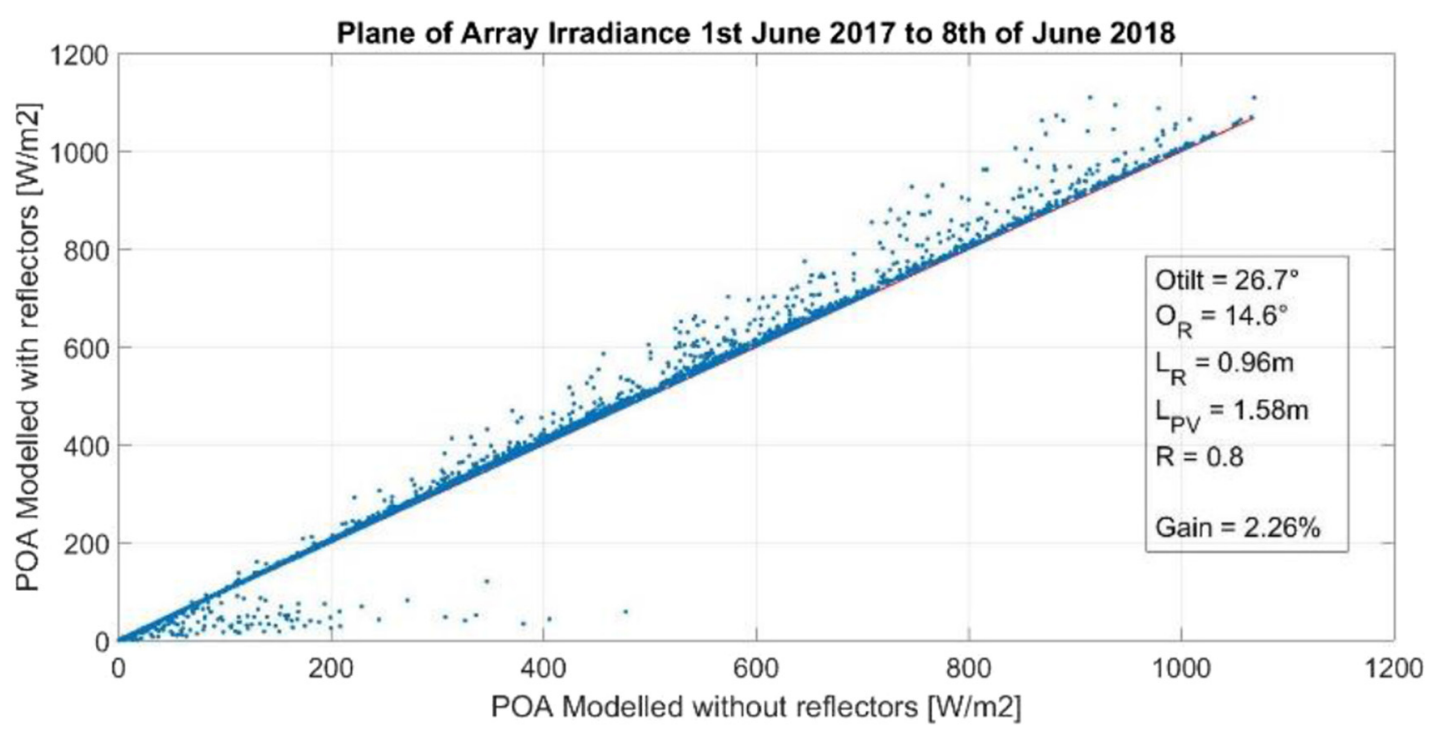

Fig. 7. Comparison between the POA irradiance with and without reflector from 1st June 2017 to 8 th of June 2018.

array and the reflector as well as a mirror's reflectivity: $\theta_{\text {tilt }}=26.7^{\circ}, \theta R=14.6^{\circ}, L_{R}=0.96 \mathrm{~m}, L_{P V}=1.58 \mathrm{~m}$ and $R$ is taken constant at 0.8 (as obtained from reflectivity measurements done in laboratory, not shown here).

Figure 7 shows the simulation results of the comparison between the POA irradiance with vs without reflectors with the same parameters used in the experimental test bench (Fig. 4). The $G_{A}$ added by the mirrors is of $2.26 \%$ over the 13 months between June 2017 and June 2018. Thus, it's obvious that in this case, the reflectors effect isn't much significant which is normal because the architecture studied here isn't optimized for a maximum efficiency. The main experimental objective was to evaluate the effect of nonuniform illumination added by the reflectors as published in a previous work [4] as well as to validate a Matlab/Simulink model we performed for electric power output prediction in case of non-uniform illumination [11]. Therefore, in order to achieve the maximum POA irradiance from the overall system leading to an efficient power generation, an optimization process is required. It is interesting to observe in the figure that there are three kinds of points that correspond to the three cases presented in Section 2.2. Case 1 would correspond to the points over the 1:1 line, for which there is a positive effect of the mirrors on the POA irradiance. Case 2 corresponds to the points on the 1:1 line, as the overexposure from the mirror do not reach the top of the panel length and thus no effect is counted. Finally, case 3 corresponds to the points for which the mirror has a negative effect, that is when the sun is behind the mirror and thus it blocks the direct component of the POA irradiance.

The following part describes a modelling optimization strategy conducted with the results achieved.

\section{Optimization strategy and results}

\subsection{Strategy}

In order to achieve higher efficiencies, an adequate PVreflector geometry as well as appropriate reflector material must be studied. In this section, we focus on the PV module-reflector architecture geometry optimization for a maximum POA irradiance reaching the modules. For that purpose, we assumed at this level a fixed ground albedo and mirror's reflectivity coefficients $\left(\rho_{g}=0.2, R=0.8\right)$. We conducted performance studies for a south oriented system in Palaiseau (France) over 13 months considering the measured GHI, BHI and DHI from SIRTA (Fig. 2). Our strategy relied on varying two major parameters affecting the plane of array irradiance: the mirror's length according to the PV module length $\left(L_{R} / L_{P V}\right)$, and the angular variation of the system ( $\theta$ tilt and $\theta_{\mathrm{R}}$ variation) as illustrated in Figure 8. For the angular variation, we considered three possibilities: a monthly variation, a seasonal variation or a fixed architecture. Each geometrical optimization procedure will result with the optimum $\theta_{\text {tilt }}$ and $\theta_{R}$ for each month corresponding to the maximum $G A$ issued from the overall system. Our optimization study relied on the particular period from June 2017 to June 2018 (Measurements and Simulation).

\subsection{Optimization results of an installation without reflectors}

The first step consisted on varying $\theta_{\text {tilt }}$ considering a conventional installation, without reflectors in order to find the optimal $\theta_{\text {tilt }}$ leading to the maximum POA irradiation for each month. Table 1 presents the results of this step.

As shown in Table 1, according to our analytical model, for a classic south oriented installation in Palaiseau, France the optimum tilt angle value varies between 21 and 30 degrees for the summer season when the sun elevation is high whereas a maximum of $6891.7 \mathrm{Wh} / \mathrm{m}^{2}$ is achieved in July. $\theta_{\text {tilt }}$ increases to reach a maximum of 63 degrees in winter when the sun is lower and we can notice the lowest $\mathrm{E}$ in December with $962.3 \mathrm{Wh} / \mathrm{m}^{2}$. During spring, an average tilt angle value can be adjusted between 28 and 34 degrees for a maximum POA incident irradiation. 


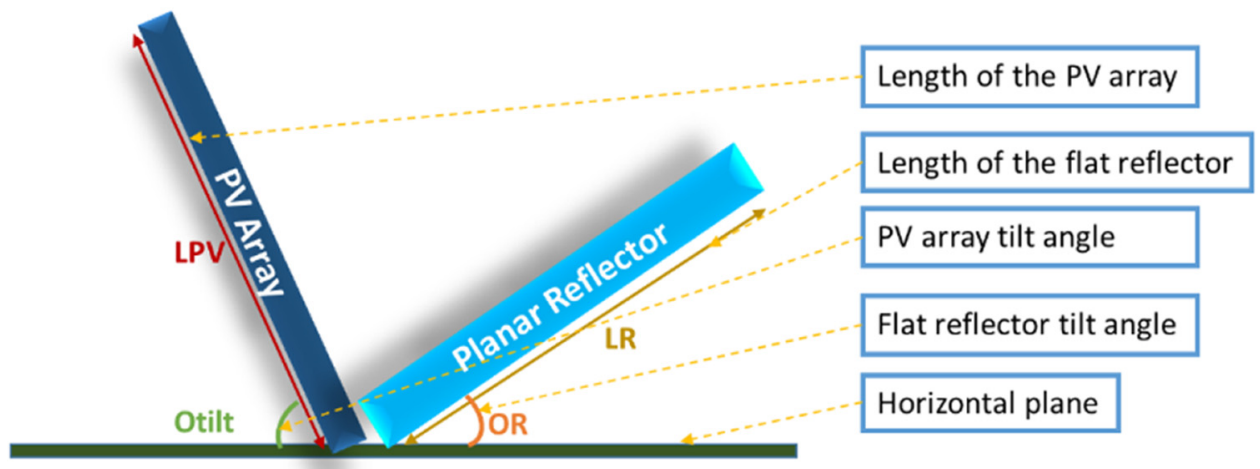

Fig. 8. Experimental platform characterized by $L_{R}, L_{P V}, \theta_{\text {tilt }}$ and $\theta_{R}$.

Table 1. Optimal $\theta_{\text {tilt }}$ corresponding to the POA max of each month for a classical installation.

\begin{tabular}{lllllllllllll}
\hline & Jun & Jul & Aug & Sept & Oct & Nov & Dec & Jan & Feb & Mar & Apr & May \\
& 2017 & 2017 & 2017 & 2017 & 2017 & 2017 & 2017 & 2017 & 2018 & 2018 & 2018 & 2018 \\
\hline E $\left(\mathrm{Wh} / \mathrm{m}^{2}\right)$ & 6891.7 & 5948.5 & 4881.8 & 3739.6 & 3322.3 & 2235.5 & 962.3 & 1152.1 & 3183.4 & 2482.2 & 4562.8 & 6251.6 \\
$\boldsymbol{\theta}_{\text {tilt }}$ Optimum $\left(^{\circ}\right)$ & 23 & 21 & 30 & 39 & 52 & 63 & 63 & 56 & 58 & 34 & 31 & 28 \\
\hline
\end{tabular}

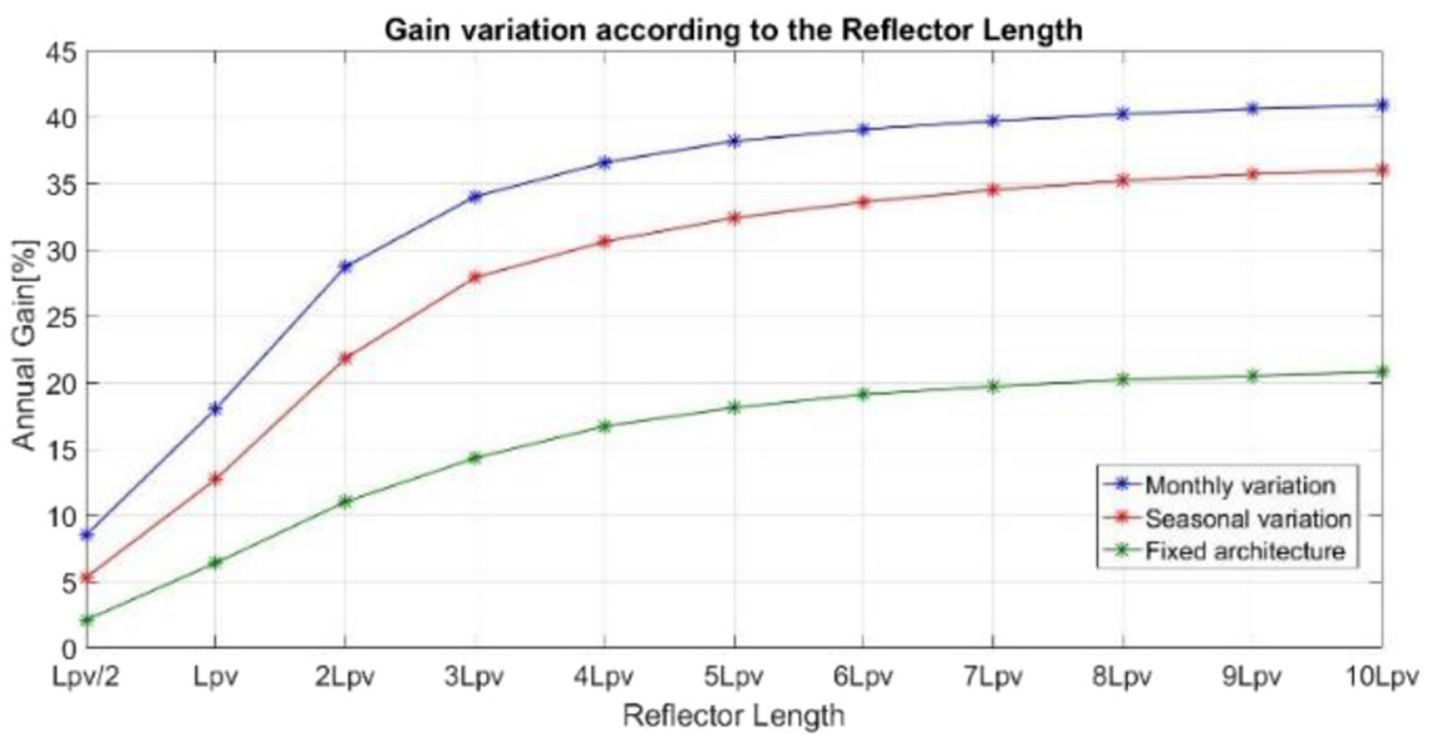

Fig. 9. $G_{A}$ variation according to the reflector's length for a monthly varied, seasonal varied and a fixed architecture.

\subsection{Optimization results of a PV-reflector installation}

In the following parts, the POA irradiation modelled at the highest point of a photovoltaic array equipped with flat reflectors is considered for our optimization process. Thus, for different reflector's lengths, we varied the array tilt angle as well as the tilt of the reflectors and we concluded the best $\left(\theta_{\text {tilt }}, \theta_{R}\right)$ combination in order to achieve a maximum POA irradiation.

First, we began by investigating our system's behavior when varying $L_{R}$ from $L_{P V} / 2$ to $10 L_{P V}$ as illustrated in Figure 9 and shown in Table 2. We repeated the same procedure for the monthly and seasonal varied as well as the fixed architectures. Our objective at this level is to find the reflector's length where $G_{A}$ begins to stabilize around a constant value. The results show that the gain increases significantly for the three cases between $L_{P V} / 2$ to $2 L_{P V}$ and continues increasing in a slower rate until reaching $8 L_{P V}$ where it stabilizes around $40 \%, 36 \%$ and $20 \%$ for the monthly, seasonal and fixed variation cases respectively. Nevertheless, other limitation constraints must be considered such as the space available for the installation as well as the inter-row distance in case of multiple rows PV installation. In the following parts only the cases of $L_{P V} / 2$, $L_{P V}$ and $2 L_{P V}$ will be considered for monthly angular variation. 


\subsubsection{Optimization according to the reflector's length 4.3.1.1 $L_{R}=L_{P V} / 2$}

First, we considered a reflector with a length half the length of the PV module (Fig. 8). The process described above is performed considering a $\theta_{R}$ that varies between $-10^{\circ}$ and $45^{\circ}$ and a $\theta_{\text {tilt }}$ between $26.7^{\circ}$ and $79^{\circ}$. The optimum results obtained are listed in Table 3.

As shown in Table 3 , for $L_{R}=L_{P V} / 2$, the maximum average of $P O A_{M i r}$ is obtained by computing the $P O A_{M i r}$ average values for each $\theta_{\text {tilt }}, \theta_{R}$ combination. This process is repeated for each month. The best combination values of $\theta_{\text {tilt }}$ and $\theta_{R}$ leading to the maximum average of $P O A_{M i r}$ irradiance are listed in Table 3. From Tables 1 and 3, a comparison between the plane of array irradiations without

Table 2. $G_{A}$ variation according to the reflector's length.

\begin{tabular}{llll}
\hline & Monthly & Seasonal & Fixed \\
$L_{R}(\mathrm{~m})$ & $G_{A}(\%)$ & $G_{A}(\%)$ & $G_{A}(\%)$ \\
\hline$L_{P V} / 2$ & 8.5 & 5.3 & 2.1 \\
$L_{P V}$ & 18 & 12.7 & 6.4 \\
$2 * L_{P V}$ & 28.7 & 21.8 & 11.0 \\
$3 * L_{P V}$ & 34.0 & 27.9 & 14.3 \\
$4 * L_{P V}$ & 36.6 & 30.6 & 16.7 \\
$5 * L_{P V}$ & 38.2 & 32.4 & 18.1 \\
$6 * L_{P V}$ & 39.1 & 33.6 & 19.1 \\
$7 * L_{P V}$ & 39.7 & 34.5 & 19.7 \\
$8 * L_{P V}$ & 40.2 & 35.2 & 20.2 \\
$9 * L_{P V}$ & 40.6 & 35.7 & 20.5 \\
$10 * L_{P V}$ & 40.9 & 36.0 & 20.8 \\
\hline
\end{tabular}

vs with reflectors is performed in order to evaluate the system's efficiency. Thus, the gain added by the planar reflectors was computed for each month.

The first step of the optimization strategy consisted on fixing the reflector's length compared to that of the PV module. Then, for each possible combination of $\left(\theta_{\text {tilt }}, \theta_{R}\right)$ calculating the ratio between the average POA irradiation obtained and the maximal average POA irradiation found over a month (Fig. 11).

Therefore, as shown in Figures 11a and 11b, the red area corresponds to the maximumPOA irradiance, from which we have defined our optimal inclination angles for each month. It is interesting to observe that, for both cases in Figure 11, there is much more sensitivity of POA irradiance to $\theta_{R}$ than to $\theta_{\text {tillt }}$. That is, changes of this latter around the maximum POA irradiance would suppose a small loss, typically less than 10\%, as shown in Figure 11.

\subsubsection{2 $L_{R}=L_{P V}$}

Here, we considered a reflector with a length equal to the length of the PV module. We repeated the same calculation process and the optimum geometrical results obtained in this case are listed in Table 4.

For $L_{R}=L_{P V}$, the best combination values of $\theta_{\text {tilt }}$ and $\theta_{R}$ leading to the maximum average of $P O A_{M i r}$ irradiation are listed in Table 4. From Tables 1 and 4, a comparison between the plane of array irradiances without vs with reflectors is performed in order to evaluate the system's efficiency.

\subsubsection{3 $L_{R}=2 \times L_{P V}$}

Finally, we considered a reflector with $L_{R}=2 \times L_{P V}$. The optimal geometrical results obtained are listed in Table 5 .

Table 3. Optimal geometrical results corresponding to the POA max for each month with $L_{R}=L_{P V} / 2$.

\begin{tabular}{lllllllllllll}
\hline$L_{R}=L_{P V} / 2$ & Jun & Jul & Aug & Sept & Oct & Nov & Dec & Jan & Feb & Mar & Apr & May \\
& 2017 & 2017 & 2017 & 2017 & 2017 & 2017 & 2017 & 2017 & 2018 & 2018 & 2018 & 2018 \\
\hline$E\left(\mathrm{Wh} / \mathrm{m}^{2}\right)$ & 7425.0 & 6301.1 & 5205.7 & 4072.0 & 3558.2 & 2261.7 & 978.0 & 1175.6 & 3318.2 & 2644.1 & 4951.7 & 6741.6 \\
$\boldsymbol{\theta}_{\text {tilt }}\left({ }^{\circ}\right)$ & 28 & 27 & 41 & 45 & 59 & 52 & 49 & 52 & 62 & 45 & 39 & 30 \\
$\boldsymbol{\theta}_{\boldsymbol{R}}\left({ }^{\circ}\right)$ & 27 & 26 & 14 & 6 & -8 & -10 & -10 & -10 & -10 & 3 & 15 & 22 \\
$\boldsymbol{G}_{\boldsymbol{M}}(\%)$ & 9.7 & 7 & 7.3 & 9.0 & 10.0 & 6.4 & 5.1 & 5.7 & 11.2 & 6.3 & 9.5 & 9.0 \\
\hline
\end{tabular}
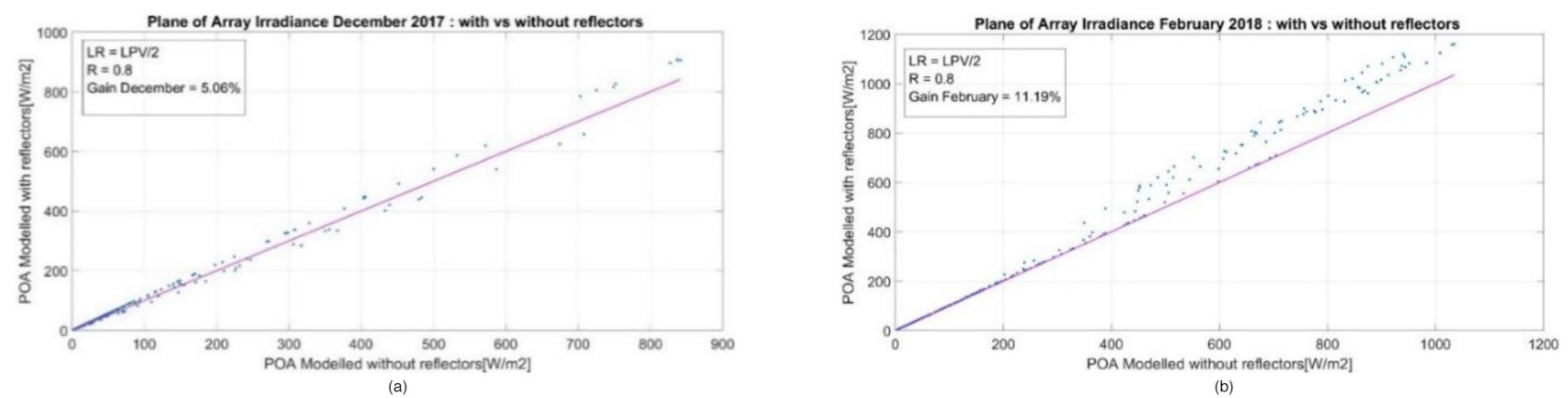

Fig. 10. Comparison between the POA irradiance with vs. without reflectors for (a) December 2017; (b) February 2018. 


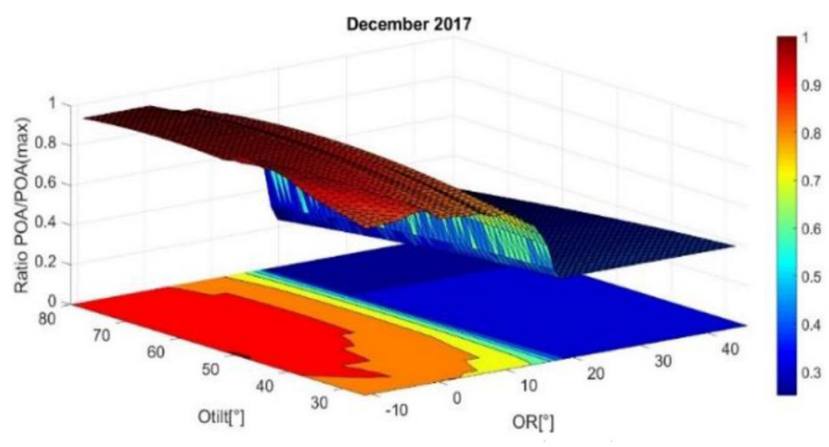

(a)

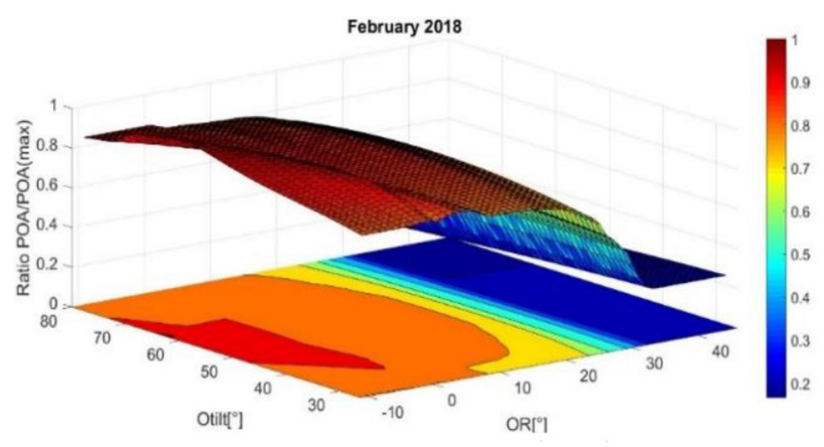

(b)

Fig. 11. Ratio between POA and POA (max) irradiances for each $\left(\theta_{t i l t}, \theta_{R}\right)$ combination over (a) December 2017; (b) February 2018.

Table 4. Optimal geometrical results corresponding to the POA max for each month with $L_{R}=L_{P V}$.

\begin{tabular}{lllllllllllll}
\hline$L_{R}=L_{P V}$ & Jun & Jul & Aug & Sept & Oct & Nov & Dec & Jan & Feb & Mar & Apr & May \\
& 2017 & 2017 & 2017 & 2017 & 2017 & 2017 & 2017 & 2017 & 2018 & 2018 & 2018 & 2018 \\
\hline$E\left(\mathrm{Wh} / \mathrm{m}^{2}\right)$ & 8007.6 & 6738.0 & 5604.5 & 4418.0 & 3945.1 & 2328.3 & 988.9 & 1202.2 & 3750.1 & 2815.4 & 5335.8 & 7307.6 \\
$\boldsymbol{\theta}_{\text {tilt }}\left({ }^{\circ}\right)$ & 30 & 27 & 45 & 47 & 66 & 64 & 62 & 61 & 71 & 46 & 48 & 39 \\
$\boldsymbol{\theta}_{\boldsymbol{R}}\left({ }^{\circ}\right)$ & 33 & 32 & 19 & 10 & -5 & -10 & -10 & -10 & -8 & 8 & 16 & 25 \\
$\boldsymbol{G}_{\boldsymbol{M}}(\%)$ & 18.4 & 14.4 & 16.7 & 18.3 & 20.3 & 18.7 & 16.5 & 14.0 & 22.7 & 13.1 & 18.8 & 19.0 \\
\hline
\end{tabular}

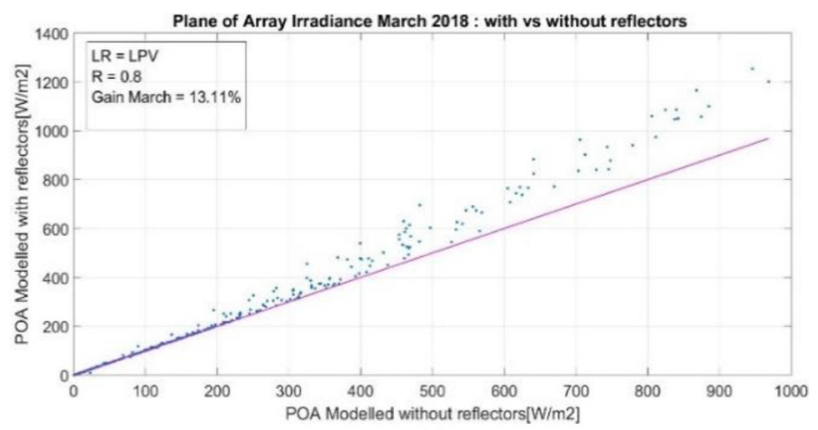

(a)

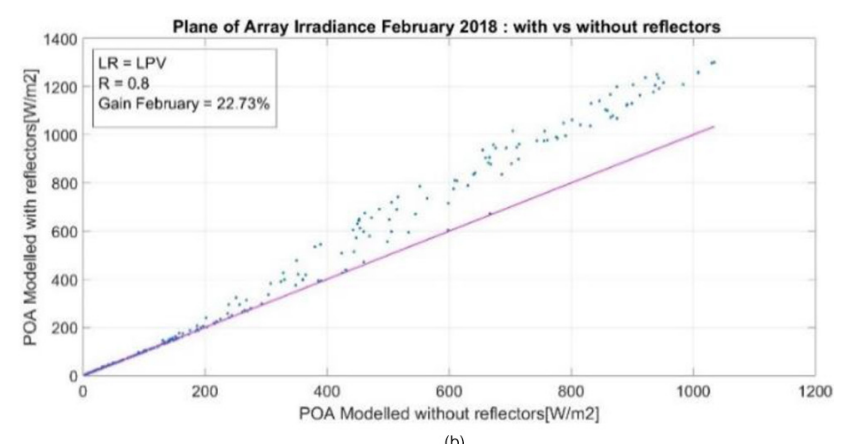

(b)

Fig. 12. Comparison between the POA irradiance with vs. without reflectors for (a) March 2018; (b) February 2018.

Table 5. Optimal geometrical results corresponding to the POA max for each month with $L_{R}=2 \times L_{P V}$.

\begin{tabular}{lllllllllllll}
\hline $\boldsymbol{L}_{\boldsymbol{R}}=2 \times \boldsymbol{L}_{\boldsymbol{P} \boldsymbol{V}}$ & Jun & Jul & Aug & Sept & Oct & Nov & Dec & Jan & Feb & Mar & Apr & May \\
& 2017 & 2017 & 2017 & 2017 & 2017 & 2017 & 2017 & 2017 & 2018 & 2018 & 2018 & 2018 \\
\hline$E\left(\mathrm{Wh} / \mathrm{m}^{2}\right)$ & 8648.1 & 7206.9 & 6070.7 & 4819.5 & 4378.3 & 2799.7 & 1141.2 & 1361.4 & 4330.2 & 3035.1 & 5804.9 & 7926.1 \\
$\boldsymbol{\theta}_{\text {tilt }}\left({ }^{\circ}\right)$ & 28 & 28 & 43 & 51 & 69 & 79 & 76 & 75 & 74 & 51 & 52 & 40 \\
$\boldsymbol{\theta}_{\boldsymbol{R}}\left({ }^{\circ}\right)$ & 42 & 40 & 28 & 17 & 2 & -6 & -9 & -6 & 0 & 14 & 24 & 34 \\
$\boldsymbol{G}_{\boldsymbol{M}}(\%)$ & 27.8 & 22.4 & 26.4 & 29.0 & 32.9 & 32.7 & 32.8 & 23.6 & 36.0 & 21.9 & 29.6 & 29.5 \\
\hline
\end{tabular}

From Tables 1 and 5 , the $G_{M}$ was computed as well in order to evaluate the system's efficiency. Figure 13 illustrates the comparison between the POA irradiance with vs without reflectors for three months from different seasons: summer (a), winter (b) and spring (c).

As shown in Figure 14, for a maximum $G_{M}$ in winter (a) where the Sun is at low elevation angles, the optimum array tilt angle increases. This variation will be in the opposite direction at summer where the sun reaches its highest elevation in June (b). We can observe as well the transitory optimal angles variation phase in spring (c). On the other hand, lowering the mirrors is of a great advantage in winter so we can get a maximum benefit from the diffuse irradiance during cloudy sky conditions. Figure 14 also shows that we are more restricted in the $\theta_{R}$ variation, as it was also the case for Figure 11 for $L_{R}=L_{P V} / 2$. 

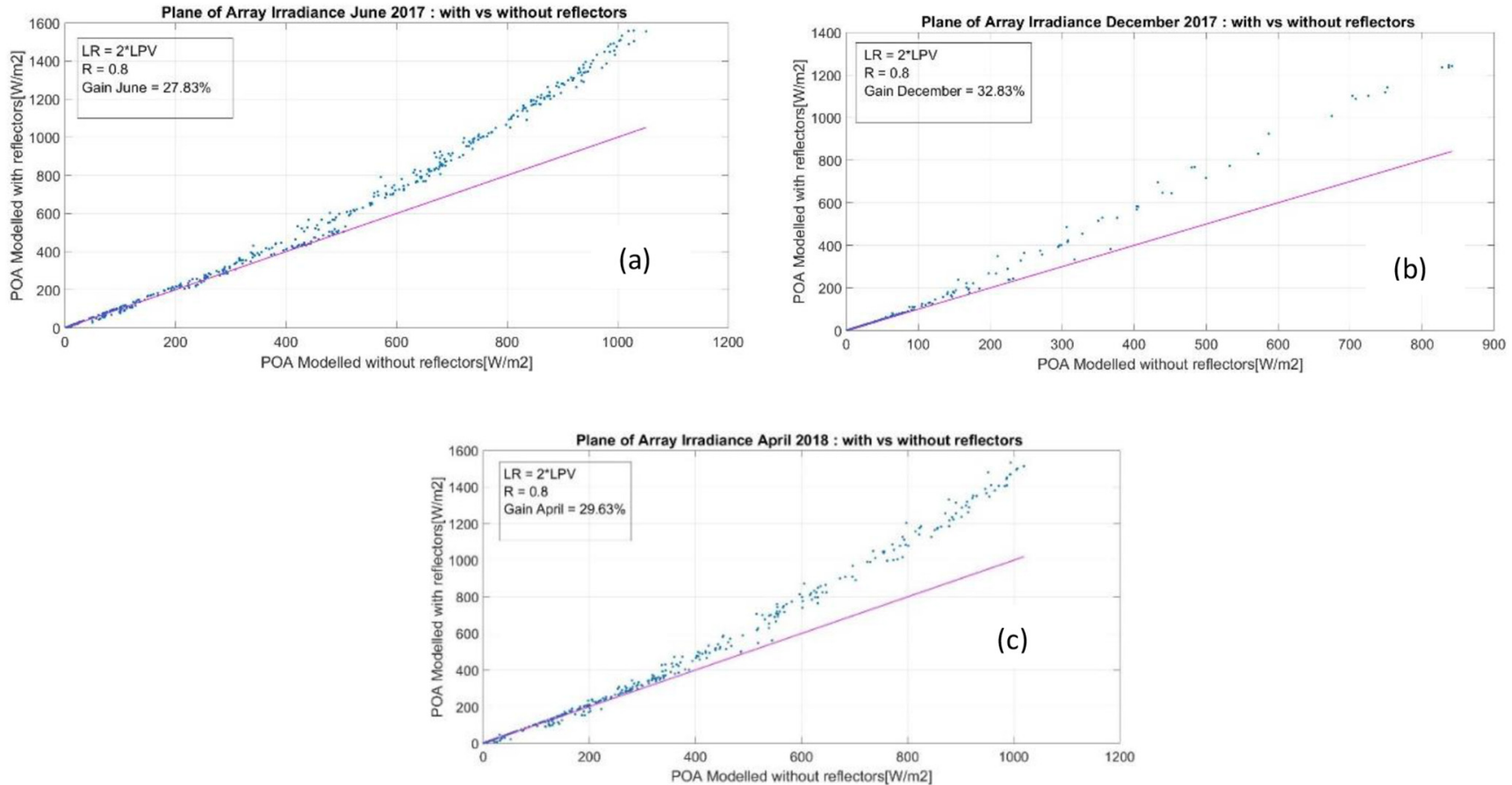

Fig. 13. Comparison between POA irradiance with vs. without reflectors, June (a), December (b) and April (c) for the case $L_{R}=2 \times L_{P V}$.
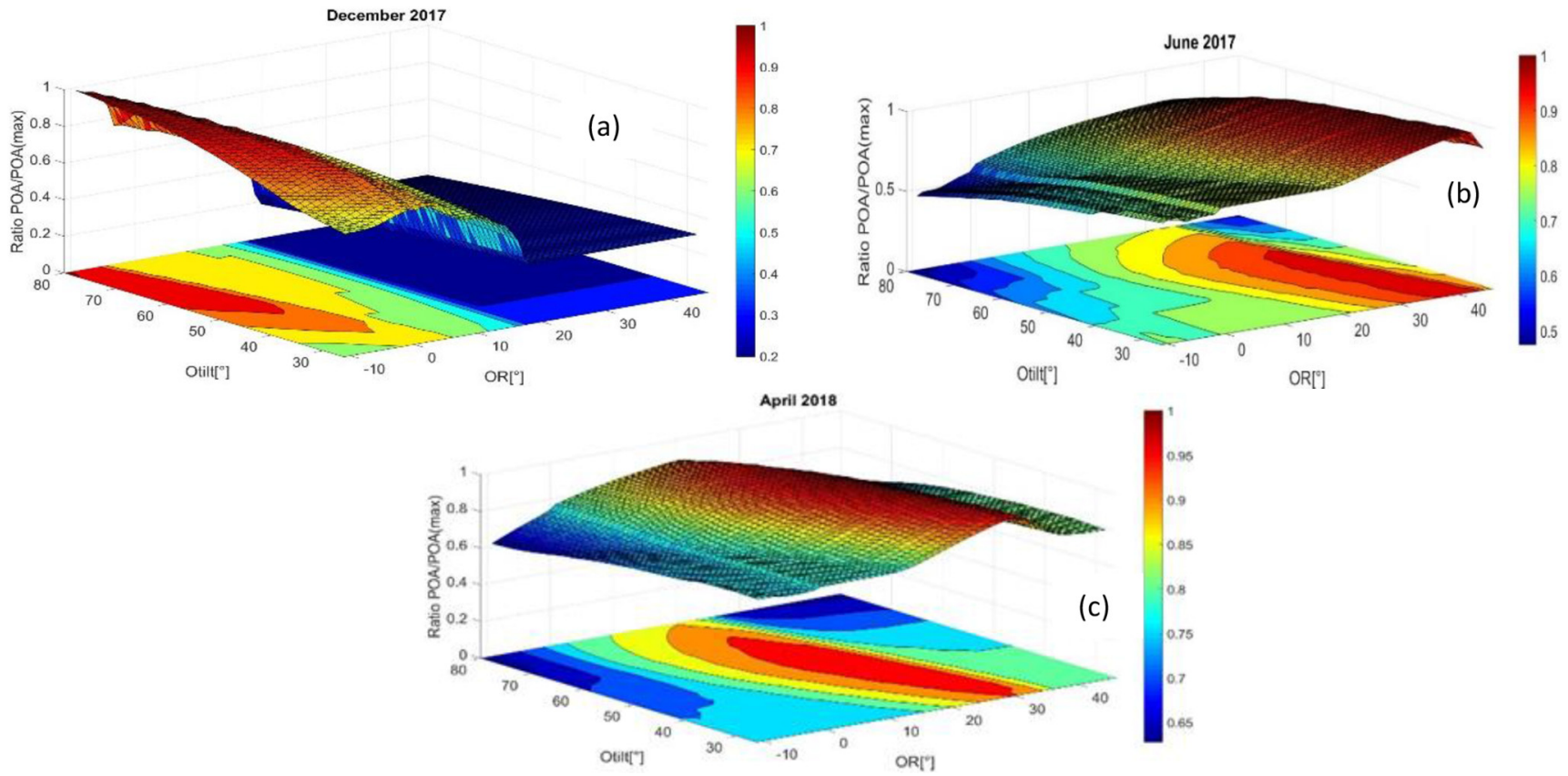

Fig. 14. Ratio between POA and POA (max) irradiances for each angles combination $\left(\theta_{\text {tilt }}, \theta_{R}\right)$ for December (a), June (b) and April (c).

\subsubsection{Discussions and analysis}

The $G_{M}$ varies between $5.1 \%$ (December 2017) and $11.9 \%$ (February 2018) for $L_{R}=L_{P V} / 2$, between $13.1 \%$ (March 2018 ) and $22.7 \%$ (February 2018) for $L_{R}=L_{P V}$ and between 21.9\% (March 2018) and 36.0\% (February 2018) for $L_{R}=2 \times L_{P V}$ as illustrated respectively in Figures 10,12 and 13. For all reflectors lengths, the energy yield reached minimum values in December and maximum values in June characterized by the highest direct normal irradiances. For the particular duration studied, $E$ varied between 978 and $8648 \mathrm{Wh} / \mathrm{m}^{2}$. The obtained gain in POA irradiation added by the flat reflectors over the year was $8.5 \%, 18.0 \%$ and $28.7 \%$ corresponding respectively to $L_{R}=L_{P V} / 2, L_{R}=L_{P V}$ and $L_{R}=2 \times L_{P V}$ architectures. Thus, comparing $G_{A}$ between $L_{R}=L_{P V} / 2$ and $L_{R}=L_{P V}$, 

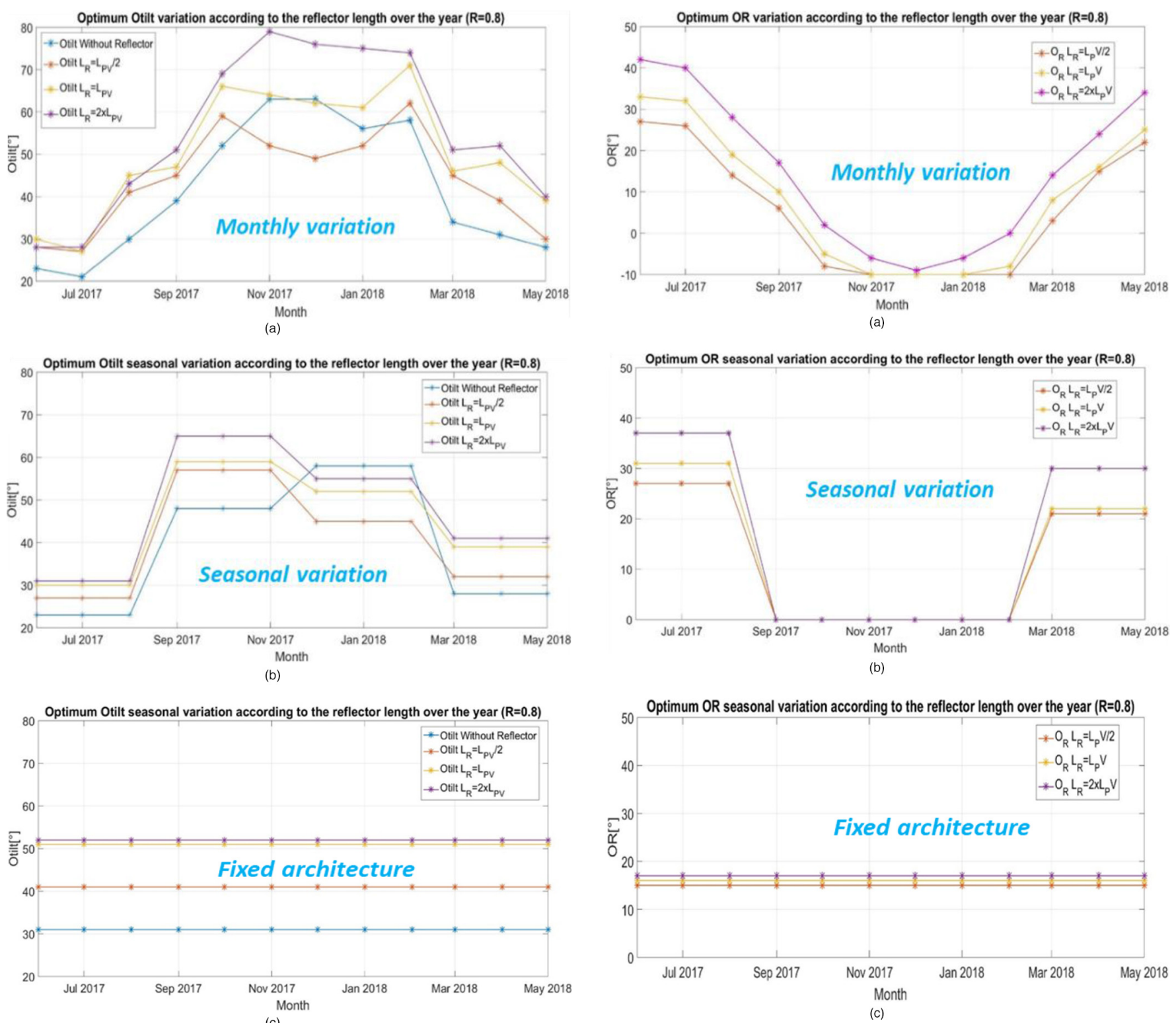

Fig. 15. Optimum $\theta_{\text {tilt }}$ over the year for (a) a monthly varied architecture; (b) a seasonal varied architecture; (c) a fixed architecture.

we can deduce a $\Delta G$ of $9.5 \%$ for the architecture with $L_{R}=L_{P V}$. Referring to the previous parts, we can say that for $L_{R}=2 \times L_{P V}$ the average $G_{M}$ has increased significantly for each month. Therefore, comparing $G_{A}$ between the architecture $L_{R}=L_{P V}$ and $L_{R}=2 \times L_{P V}$, we can deduce a $\Delta G$ of $10.7 \%$ for the architecture with $L_{R}=2 \times L_{P V}$.

Thus, at the end of this part, we can definitely say that the geometrical architecture design highly affects the efficiency of such system. The results obtained can highlight the importance of the flat reflectors length in order to achieve the higher incident POA irradiation. We found that an increase in the mirrors length was increasing the average outcome.

Fig. 16. Optimum $\theta_{R}$ over the year for (a) a monthly varied architecture; (b) a seasonal varied architecture; (c) a fixed architecture.

\subsubsection{According to the angular variation}

In this part, the optimization variable considered is the angular variation frequency for a fixed reflector's length. Thus, we first set $L_{R}=L_{P V} / 2$ and computed the optimal $\theta_{\text {tilt }}$ and $\theta_{\mathrm{R}}$ combination considering: a monthly angular variation, a seasonal angular variation and a fixed architecture (constant $\theta_{\text {tilt }}$ and $\theta_{\mathrm{R}}$ over the entire period). We computed the $G_{M}$ for each month as well as $G_{A}$ for each variation at the end of the optimization process. The same procedure was repeated for $L_{R}$ fixed to $L_{P V}$ and finally to $2 \times L_{P V}$.

Figures 15 and 16 representing optimum $\theta_{\text {tilt }}$ and $\theta_{R}$ values show that during winter, it is more efficient to increase the PV array tilt angle and lower the reflector which is normal since the sun elevation is low as explained 


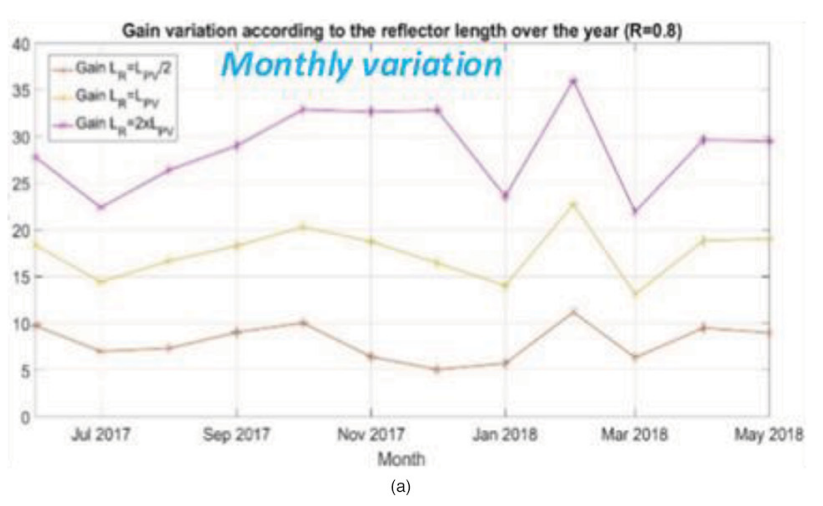

\begin{tabular}{|c|c|c|}
\hline$L_{R}(m)$ & $G_{A}(\%)$ & $\Delta G(\%)$ \\
\hline $\mathrm{L}_{\mathrm{PV}} / 2$ & 8.5 & - \\
\hline $\mathrm{L}_{\mathrm{PV}}$ & 18.0 & 9.5 \\
\hline $2 * \mathrm{~L}_{\mathrm{PV}}$ & 28.7 & 10.7 \\
\hline
\end{tabular}

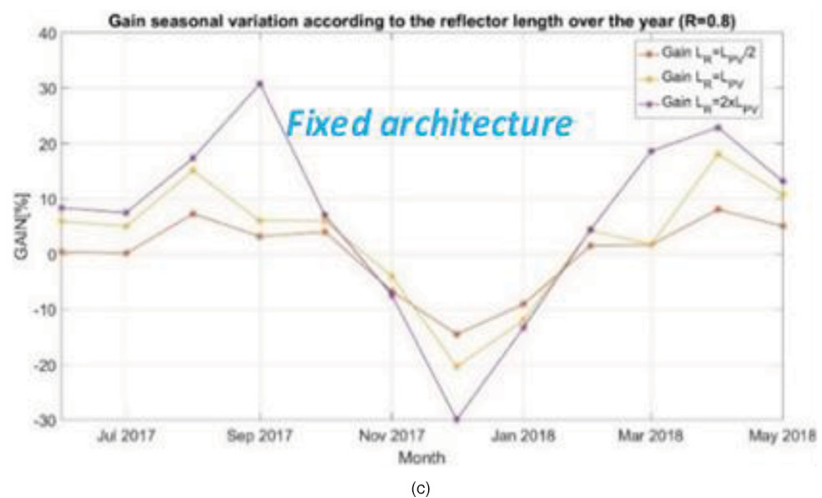

Fig. 17. Gain variation according to the reflector's length over the year for (a) a monthly varied architecture; Gain variation according to the reflector's length over the year for (b) a seasonal varied architecture; (c) a fixed architecture.

previously. It is the opposite case during summer. In addition, the annual variation cycles for $\theta_{\text {tilt }}$ and $\theta_{R}$ vary in opposite directions.

As highlighted in Figure 15, the longer the mirror is, it is better to straighten the PV in order to increase the $G_{A}$ (to achieve the maximal outcome from the reflected rays of the mirrors).

As illustrated in Figure 17 representing the $G_{A}$ evolution compared to a PV installation without reflectors, the POA irradiation gain doubles from $L_{R}=L_{P V} / 2$ to $L_{R}=L_{P V}$ for a monthly and seasonal varied architectures and triples for the fixed one. Nevertheless, it is not the same variation behavior going from $L_{R}=L_{P V}$ to $L_{R}=2 \times L_{P V}$ where the gain increasing ratio is lower. In fact, the larger we extend the length of the mirrors beyond the PV module length, the shading effect increases on one hand and there will be a part of the mirror's surface reflecting rays that won't be absorbed by the PV arrays on the other hand, which justifies that result. Actually, it is well shown in Table 2 and Figure 9 that when making $\mathrm{L}_{R}$ larger, the gain increase gets lower. Considering $L_{R}=L_{P V}$, we can notice a $\Delta G$ of $6 \%$ from the seasonal to the monthly

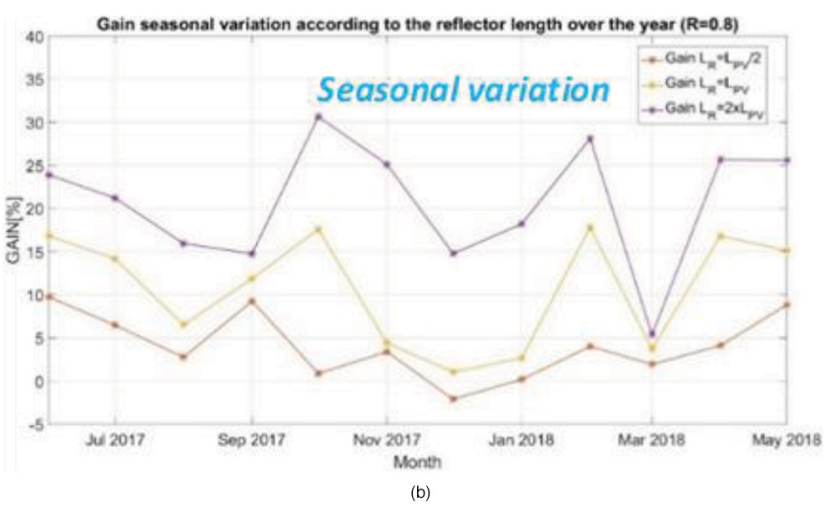

\begin{tabular}{|c|c|c|}
\hline$L_{R}(m)$ & $G_{A}(\%)$ & $\Delta G(\%)$ \\
\hline $\mathrm{L}_{\mathrm{PV}} / 2$ & 5.3 & - \\
\hline $\mathrm{L}_{\mathrm{PV}}$ & 12.7 & 7.4 \\
\hline $2 * \mathrm{~L}_{\mathrm{PV}}$ & 21.8 & 9.1 \\
\hline
\end{tabular}

\begin{tabular}{|c|c|c|}
\hline$L_{R}(m)$ & $G_{A}(\%)$ & $\Delta G(\%)$ \\
\hline $\mathrm{L}_{\mathrm{PV}} / 2$ & 2.1 & - \\
\hline $\mathrm{L}_{\mathrm{PV}}$ & 6.4 & 4.3 \\
\hline $2 * \mathrm{~L}_{\mathrm{PV}}$ & 11.0 & 4.6 \\
\hline
\end{tabular}

varying architectures and we can observe the same $\Delta G$ going from the fixed to the seasonal varying architecture.

Furthermore, we compared the annual gain between angular adjustment frequencies of PV-reflectors installations. According to the results obtained, a monthly-varied architecture has significant advantage over seasonal varied and fixed ones increasing the annual gain to $28.2 \%$ and $31.6 \%$ respectively. On the other hand, a seasonal varied architecture impact isn't much valuable over a fixed architecture with a $2.6 \%$ added annual gain. Nevertheless, it's important to mention that these obtained results depend on our specific case study including the weather conditions that characterized the period between June 2017 and June 2018 in Palaiseau. Thus, the obtained results cannot be completely generalized and an accurate study depending on each site must be performed in order to adopt the most efficient PVreflector system.

Therefore, the best geometrical optimization of such an installation will depend on several factors such as geographical conditions and the accessibility to the installation allowing an adequate angular variation as well as several economic constraints. 


\section{Conclusion}

In this paper, a plane of array irradiance estimation model was developed and validated experimentally via our platform installed at SIRTA observatory in the case of a classical PV installation system as well as in case of an installation equipped with flat reflectors. The modelling simulation results were compared to measurements over two periods with and without reflector. During the considered 13 months, the mean absolute errors obtained were $6 \%$ and $7 \%$ for a classical PV system and a PVreflector system respectively. Mean bias error values were lower than $1 \%$ in both cases.

Furthermore, an architectural optimization process was developed through this POA irradiance estimation model. A simulation analysis has been presented for all months over a year in order to find the geometrical parameter's combination $\left(\theta_{\text {tilt }}, \theta_{R}\right.$ and $\left.L_{R}\right)$ insuring the higher POA incident irradiation on the PV array. The simulation results showed that the length of the mirrors highly affects the efficiency and performances of the PVReflector system. In fact, the annual gain increased from $8.5 \%$ to $28.7 \%$ when going from $L_{R}=L_{P V} / 2$ to $L_{R}=2 \times L_{P V}$ compared to a monthly-optimized installation without mirrors. Nevertheless, depending on each installation dimensional requirements, many construction constraints must be taken into consideration and the gain in irradiance doesn't vary in a proportional way with the length of the mirrors. This is because of the shading effect resulting with an activation of bypass diodes and because of the part of the reflected rays that won't reach the PV module as well.

The second part of our geometrical optimization process consisted on fixing the reflector's length and evaluating our system's applicability according to a monthly or a seasonal angular variation or a fixed PVreflector architecture. The results obtained in this part showed that for our case study, a monthly-varied architecture is the most advantageous option with a 28.2 and $31.6 \%$ increasing in annual gain compared to a seasonal varied and fixed one respectively. Thus, in the presented case, for a small PV installation with an adjustable structure, it won't be difficult to adjust the inclination angles manually every month without additional costs. Nevertheless, a system's performance assessment should be conducted separately for each case study and location depending on the geographical, technical and economic aspects. Limitations regarding the available space and inter-row distance if we have an installation with several PV modules rows must be considered as well.

Regarding the economical evaluation: we performed a study on a type of reflector, similar to aluminium foils costing around 1 euro per $\mathrm{m}^{2}$ and the experimental performance results we obtained were satisfying. It's important to mention here that this gain in irradiance will vary with geographical locations. For instance, we conducted a further study where we found that the annual gain in POA irradiance could reach $35 \%$ in Athens, thus increasing the economic advantage of such a system.
Finally, a deeper optimization process will be conducted taking additional system's aspects and properties into consideration such as mirror's nonlinear reflectivity factor depending on the materials characteristics. An optimized electrical power output estimation considering the non-uniform illumination brought by such installation on the PV array will be presented in a future work. For that purpose, an experimental platform is under construction at GeePs laboratory in order to test our optimization results for the different geometrical configurations of PV-reflector architectures.

\section{Nomenclature}

AOI Angle of incidence of the Sun rays on the PV module $\left(^{\circ}\right)$

$\mathrm{AOI}_{R, P V}$ Angle of incidence of the reflected beam to the PV module $\left(^{\circ}\right)$

$\mathrm{AOI}_{R} \quad$ Angle of incidence of the Sun rays on the reflector $\left(^{\circ}\right)$

BHI Beam Horizontal Irradiance $\left(\mathrm{W} / \mathrm{m}^{2}\right)$

BNI Beam Normal Irradiance $\left(\mathrm{W} / \mathrm{m}^{2}\right)$

CPV concentrator photovoltaic

DHI Diffuse Horizontal Irradiance $\left(\mathrm{W} / \mathrm{m}^{2}\right)$

DRBI Direct reflected beam irradiance $\left(\mathrm{W} / \mathrm{m}^{2}\right)$

DPSR Diffuse reflected solar radiation $\left(\mathrm{W} / \mathrm{m}^{2}\right)$

E Solar Irradiation $\left(\mathrm{Wh} / \mathrm{m}^{2}\right)$

$\mathrm{G}_{A} \quad$ Annual gain in POA irradiance (\%)

$\mathrm{G}_{M} \quad$ Monthly gain in POA irradiance added

by the reflectors (\%)

GHI Global Horizontal Irradiance $\left(\mathrm{W} / \mathrm{m}^{2}\right)$

GRISR Ground reflected incident solar radiation $\left(\mathrm{W} / \mathrm{m}^{2}\right)$

$\mathrm{L}_{\mathrm{PV}} \quad$ Photovoltaic array length $(\mathrm{m})$

$\mathrm{L}_{R} \quad$ Reflector Length (m)

MAE Mean absolute error

MBE Mean bias error $\left(\mathrm{W} / \mathrm{m}^{2}\right)$

POA Plane of array irradiance per month $\left(\mathrm{W} / \mathrm{m}^{2}\right)$

$\mathrm{POA}_{\text {year }}$ Plane of array irradiance per year $\left(\mathrm{W} / \mathrm{m}^{2}\right)$

POA $_{\text {Mir }}$ Plane of array irradiance with mirrors $\left(\mathrm{W} / \mathrm{m}^{2}\right)$

$\mathrm{R} \quad$ Reflectivity of the mirrors

RMAE Relative mean absolute error

RMBE Relative mean bias error

$\mathrm{VF}_{P V R} \quad$ View Factor from the PV module to the reflector

$\mathrm{VF}_{R P V} \quad$ View Factor from the Reflector to the PV module

$\theta_{a} \quad$ Solar Azimuth angle $\left(^{\circ}\right)$

$\theta_{\text {a,array }} \quad$ Azimuth array angle $\left(^{\circ}\right)$

$\theta_{e l} \quad$ Sun Elevation angle $\left(^{\circ}\right)$

$\theta_{P V, R} \quad$ Angle between the PV module and the reflector $\left(^{\circ}\right)$

$\theta_{R} \quad$ Angle between the reflector and the horizontal plane $\left(^{\circ}\right)$

$\theta_{\text {tilt }} \quad$ Inclination angle of the PV module to the horizontal plane $\left(^{\circ}\right)$

$\theta_{Z} \quad$ Solar zenith angle $\left(^{\circ}\right)$

$\rho g \quad$ Ground reflectance (albedo), it represents

a part of the reflected radiation

$\Delta_{G} \quad$ The gain difference issued from an optimization procedure (\%) 
This work was partly supported by the TREND-X research program on energy transition of Ecole Polytechnique.

\section{References}

1. C. Abdel Nour, A. Migan-Dubois, J. Badosa, V. Bourdin, C. Marchand, T. Akiki, Etude de l'effet du sur-éclairement non uniforme sur les performances d'une installation photovoltaïque équipée de réflecteurs plans, in JNPV, Dourdan, France, 2017

2. M. Pavlov et al., IEEE Journal of Photovoltaics 5, 1686 (2015)

3. J. Gelegenis, P. Axaopoulos, S. Misailidis, G. Giannakidis, M. Samarakou, B. Bonaros, Feasibility for the use of flat booster reflectors in various photovoltaic installations, Int. J. Renew. Energy Res. 5, 82 (2015)

4. J. Badosa et al., Deployment of a multi-technology photovoltaic module test bench on the SIRTA meteorological and climate observatory, in 31st European PV Solar Energy Conference and Exhibition (Eu-PVSEC), Hambourg (Germany), September 2015

5. EU Solar Market Grows 36\% in 2018. SolarPower Europe (blog). Available at: http://www.solarpowereurope.org/eusolar-market-grows-36-in-2018/ Accessed March 6, 2019
6. M. Rönnelid, B. Karlsson, P. Krohn, J. Wennerberg, Booster reflectors for PV modules in Sweden, Prog. Photovoltaics 8, 279 (2000)

7. M. Boyd, Analytical model for solar irradiance near a planar vertical diffuse reflector - formulation, validation, and simulations, Solar Energy 91, 79 (2013)

8. W. Andrews, Rob, A. Pollard, J. Pearce, Photovoltaic system performance enhancement with non-tracking planar concentrators: experimental results and BDRF based modeling, in Conference Record of the IEEE Photovoltaic Specialists Conference, 2013. https://doi. org/10.1109/PVSC.2013.6744136

9. M. Haeffelin, L. Barthès, O. Bock, C. Boitel, S. Bony, D. Bouniol, P. Drobinski, SIRTA, a ground-based atmospheric observatory for cloud and aerosol research, Ann. Geophys. 23, 253 (2005)

10. BSRN, http://bsrn.awi.de

11. C. Abdel Nour et al., Photovoltaic system equipped with flat reflectors: new MPPT model in case of non-uniform illumination on PV modules, in 35th European PV Solar Energy Conference and Exhibition (Eu-PVSEC), Brussels, Belgium, September 2018

12. J.A. Duffie, W.A. Beckman, Solar Engineering of Thermal Processes, 4th edn. (Wiley, 2013). https://www.wiley.com/ en-cu/Solar

Cite this article as: Christine Abdel Nour, Anne Migan-Dubois, Jordi Badosa, Vincent Bourdin, Claude Marchand, Tilda Akiki, Geometrical optimization for a photovoltaic installation equipped with flat reflectors based on plane of array estimations, EPJ Photovoltaics 11, 1 (2020) 